\title{
Comment
}

\section{Territorial Need Indicators: A Comment}

\author{
DOREEN IRVING*
}

Bebbington and Davies (1980) claim that the usefulness of territorial need indicators has been weakened by disregard of theory. They argue that a theoretical basis for need indicators may be found in need judgements viewed as cost-benefit decisions. Translation of theory into practice would be straightforward if costs and benefits could always be measured but since they cannot the merits or otherwise of the Bebbington and Davies approach must depend on the circumstances in which their method is applied and on the data and procedures used. The authors accept that all indicators are to some degree influenced by availability of data (p. 147). They do not recognise that the usefulness of any method including their own must be assessed in relation to practical limitations. Fortunately, the authors give an example to illustrate their method. Briefly, I understand that method to combine three elements: needs, services, costs of services. The concept of need judgement integrates needs, services and costs by supposing that resources are insufficient to satisfy every identifiable need and that priorities must be derived from a consideration of the benefits and costs of services. Social services provision for the elderly is the example presented in detail by the authors. The circumstances in which the method is to be applied and the data and procedures to be used are explicit enough to allow evaluation and comparison with rival methods. Analysis of their example casts doubt upon not only the appropriateness of their choice of data and procedures but also the feasibility of making practical use of the theory of need judgements as expounded in their paper.

Before descending into data and procedures let us consider why territorial need indicators may be of use for personal social services for the elderly. In central government, a device for increasing the rationality of rate support grant calculations is likely to be welcomed by officials and perhaps by ministers. In local authorities, rational techniques may also

\footnotetext{
* Lecturer, Department of Social Science and Administration, London School of Economics.
} 


\section{Doreen Irving}

be of use in the complicated process of achieving optimum and equitable resource allocation between area offices and between groups of clients. Unlike some indicators used for resource allocation the method proposed by Bebbington and Davies requires priorities to be specified. Local authority priorities might differ from those of central government. The existence of a mismatch between assumptions incorporated into rate support grant calculations and the intentions or practices of local authorities contradicts the supposed rationality of the formula. Expenditure cuts also create circumstances which are highly unfavourable to extensive rational specification. In their example, Bebbington and Davies make a series of compromises assuming, for instance, that the distribution of total expenditure between services for the elderly (home helps, meals on wheels, day centre places, residential accommodation) would be the same in 1980 as in 1975. Their assumption of no change in relative spending arises either from an absence of a policy to bring about a change or from an inability to quantify required changes in the balance of services. A distinction should be made between assumptions reflecting policy decisions and assumptions reflecting an unwillingness or inability to quantify in sufficient detail the implications of policies. The dilemma posed by the method advocated by Bebbington and Davies is that the opportunity to incorporate policy decisions in the model may turn into a gateway for dubious assumptions. Such assumptions or compromises the authors claim are made necessary by the state of the data and are not inherent in the method (p. 441), ignoring the possibility that an all purpose theory may be less use in practice than a problem oriented approach where the degree of elaboration of theory and method are carefully tailored to match existing knowledge.

It is unrealistic to suppose that a social services department could have detailed knowledge of the needs of every elderly resident within a local authority boundary. A compromise would be to define target groups based on categories of need, to specify a mix of services appropriate for each target group member, to estimate the number of individuals in each target group, and to combine this information with unit costs of services to calculate financial implications. Assuming that resources fall short of what is ideally required an appraisal of costs and benefits would enable services for target groups to be aligned with available funding. In a local authority there may be some merit in the method outlined which is that advocated by Bebbington and Davies. Nationally, the circumstances are different because even if central government had as much information as local authorities, and were able to produce optimum allocation plans for target groups, local authorities would not be obliged to implement 
those plans. The authors blur the important distinction between national and local contexts by subsuming them in a policy paradigm (p. 457).

My main objection is to the method of estimating the size of each target group. Four need categories (no need, moderate needs, considerable needs, intense needs) are used as criteria for target groups. Leaving aside the surprising reduction of needs of the elderly into a mere four categories and the difficulty which might arise in particular cases of deciding whether an individual belonged to one category or another, by what process is an estimate made of numbers in each target group in each local authority? Such numbers are not generally known although some local authorities have carried out extensive studies. Statistics from the census fill the gap with a technique known as synthetic estimation. Relationships are first established in survey data between what is to be estimated, namely, the size of each target group, and what is recorded in the census. The relationships are in the form of regression equations fitted to information collected in local authority surveys of the elderly. Age and living alone are the most significant variables in equations which include sex, marital status, household composition, tenancy, and bathroom facilities (p. 448). Census figures are available for each of these variables in every local authority in England and Wales, and relationships between need category and census variables are known in the form of regression equations for selected authorities. A synthesis of census figures and regression equations produces estimates of the size of each target group in each local authority.

To see what is wrong with these estimates consider why the elderly need social services. The chief reasons are frailty in old age and inadequacy of family help. Not surprisingly, the most significant variables in the regression equations are age and living alone because these are crude indicators of frailty and lack of help. Some of the other variables included in the equations lack any logical connexion with need for social services; for instance, an owner occupier is neither more nor less likely to need help than a council tenant. Some elderly owner occupiers may have inferior housing compared with council tenants, and vice versa. If owner occupation were an indication of income it might be argued that private help could be bought, but it would be wrong to suppose that elderly owner occupiers have high incomes. The relationship between need category and tenancy as measured by a regression coefficient is likely to show considerable variation between local authorities. Ambiguous indicators of need such as tenancy make regression equations less robust. Intercorrelation among census variables also reduces the stability of the regression equations. Examples of correlation are that women tend to live 


\section{Doreen Irving}

longer than men, and that married people are less likely to be living alone than the single, widowed or divorced. There is a case therefore for parsimony in choosing census variables to ensure that the variables are unambiguously related to need and uncorrelated. Considering the importance which Bebbington and Davies attach to theory their empiricism in choosing census variables is remarkable.

The purpose of synthetic estimation is to measure the size of target groups. The information is needed to enable appropriate services to be planned. Such planning should recognize financial limits and be sensitive to geographical variations in unit costs of services. The method proposed by Bebbington and Davies could assist rational planning by enabling the implications of various options to be discussed by policy makers and service providers. Assuming that categorization of need into four groups is meaningful and that total funding and unit costs of services are known, the mix of services corresponding to priorities among target groups can be placed within the budgetary constraint and assessed by a judicious though unquantified appraisal of the benefits of alternative patterns of service provision. It makes far more sense to carry out such an exercise within local government where decisions are made than in central government which partly finances social services but has little control over the mix of services provided. It is in relation to the national distribution of rate support grant, however, that Bebbington and Davies choose to illustrate their method. How do they decide upon allocation plans for target groups? First, they derive alternative plans from social services research literature: these plans could not have taken full account of later financial realities or of geographical variations in unit costs. Second, they make an assumption that national aggregate spending on each service would remain the same in relative terms; for instance, twice as much was spent in $1975 / 6$ on day centre provision as on meals on wheels, and this ratio is assumed to continue. Third, they estimate variations in unit costs by regression equations which in my view are unduly complicated (p. 452). Fourth, the planned allocations to each target group are scaled to match actual spending on each service in 1975/6 while taking account of regression estimates of unit costs. This mechanistic process provides little opportunity to exercise judgement.

The authors are aware of imperfections in their example, but is their method better than other techniques used in central government? The RAWP formula, for instance, eschews an explicit specification of priorities and has no need for synthetic estimation. A similar approach could be adopted for rate support grant calculations, or empirical indicators could be used as in the past. In the circumstances of its application, the new 
approach to territorial need indicators presented by Bebbington and Davies is not an advance in practice whatever its putative merits in theory.

\section{REFERENCES}

A. C. Bebbington and Bleddyn Davies, 'Territorial need indicators: a new approach', Journal of Social Policy, part I, 9:2 (April 1980), 145-68; part II, 9:4 (October 1980), 433-62. 